\title{
O BILINGUISMO POMERANO E PORTUGUÊS NA SERRA DOS \\ TAPES, RS, COMO CARACTERÍSTICA SOCIOCULTURAL
}

\author{
THE POMERANIAN AND PORTUGUESE BILINGUALISM IN THE \\ “SERRA DOS TAPES”, RS, BRAZIL, AS A SOCIOCULTURAL \\ CHARACTERISTIC
}

Luís Isaías Centeno do Amaral ${ }^{1}$, Daiane Mackedanz ${ }^{2}$

\begin{abstract}
RESUMO: A Serra dos Tapes, sul do RS, apresenta contingente de imigrantes europeus, em sua maioria pomeranos, provenientes da antiga e extinta Pomerânia. Seus descendentes ainda falam o pomerano, lingua trazida ao Brasil com os imigrantes. O bilinguismo português $e$ pomerano é, assim, uma característica da região, especialmente na comunidade interiorana e rural de Santa Augusta. Neste artigo, analisamos, à luz da Linguística Antropológica e da Sociolinguística Variacionista, a situação de contato linguístico entre o pomerano e o português. $O$ bilinguismo é elemento crucial para a compreensão não somente dos usos linguísticos e de fenômenos variacionistas do PB na localidade, como também para a compreensão das relações socioculturais e, especialmente, elemento chave para a constituição da identidade dos sujeitos bilíngues. Desse modo, o espectro "características socioculturais, bilinguismo, identidade" influencia as representações socioculturais e os usos bilíngues dos moradores de Santa Augusta, podendo contribuir, assim, para a manutenção do pomerano.
\end{abstract}

PALAVRAS-CHAVE: Pomerano; Bilinguismo; Identidade.

ABSTRACT : Serra dos Tapes, in the South of Rio Grande do Sul, is a place that received a contingent of European immigrants in the $18^{\text {th }}$ century, most of them were Pomeranians, coming from the ancient Pomerania. The descendants of them still speak Pomeranian, language brought to Brazil with the immigrants. Currently, Portuguese and Pomeranian's Bilingualism is a characteristic of Serra dos Tapes, especially in the rural community of Santa Augusta. In this work, we analyze, through Anthropological Linguistics and Sociolinguistics, the contact situation between Pomeranian and Portuguese. Bilingualism is the main element to understand that the linguistic use and the variation phenomena from Brazilian Portuguese in that place do not bring all the answers. As well, the study of bilingualism helps us to understand social and cultural relationship between the subject's bilingual identities constitution. Thus, the spectrum "social cultural characteristics, Bilingualism, identity" influences semantic representations and linguistic uses of the habitants of Santa Augusta; and this contributes, therefore, to the Pomeranian maintenance.

\footnotetext{
${ }^{1}$ Doutor em Letras pela UFRGS. Docente da Universidade Federal de Pelotas (UFPel).

${ }^{2}$ Mestre em Letras pelo Programa de Pós-Graduação em Letras da UFPel.
} 
KEYWORDS: Pomeranian; Bilingualism; Identity.

\section{Introdução}

O Brasil é considerado, segundo Morello (2015), um dos países mais ricos em diversidade linguística do planeta. Antes de 1500, aqui eram faladas centenas de línguas indígenas; e ao longo dos mais de 500 anos, desde o descobrimento, diferentes populações aqui aportaram, trazendo consigo suas línguas. Conviveram, comunicaram-se e se misturaram aqui povos ameríndios, americanos, africanos, europeus e asiáticos (ALTENHOFEN; RASO; MELLO, 2011). Assim, o bilinguismo e o bidialetalismo (ou mesmo o multilinguismo e o multidialetalismo) caracterizam nossos usos linguísticos e são decorrência do histórico brasileiro de contatos linguísticos.

Os fenômenos de bilinguismo em zonas urbanas (médias a grandes) não são preponderantes no Brasil, o que contribui para que haja uma visão hegemônica sobre o domínio absoluto do português. Isso não permite que se tenha consciência da existência do bilinguismo em comunidades de etnias diversas (GROSJEAN, 1982), No Rio Grande do Sul, especialmente, conforme Vandresen (1995), Pinho (2008), Silva (2011) e Mujica (2013), há comunidades bilíngues que refletem a história desses contatos linguísticos: ainda há grupos étnicos com descendência germânica que usam, em sua comunicação cotidiana in-grupo, uma língua distinta do português brasileiro.

Neste artigo, discutiremos parte dos resultados da pesquisa de mestrado, realizada na comunidade rural de Santa Augusta, localizada no município de São Lourenço do Sul, RS. Trata-se de uma localidade situada na Serra dos Tapes (sul do RS) e que possui como umas das principais características a presença de descendentes de imigrantes europeus, em sua maioria pomeranos. Estes vieram da hoje extinta Pomerânia ${ }^{3}$ e aportaram na região da Serra dos Tapes em 1858. Sua língua, de origem baixo-saxônica, era falada na Pomerânia e ainda o é em diversos municípios da região sul do RS e outros estados brasileiros, o que será melhor esclarecido na próxima seção. Desse modo, enfocamos neste artigo, o caso de contato linguístico entre o pomerano e o português na comunidade de Santa Augusta.

Conforme estudos de Mujica (2013), entendemos tratar-se de uma comunidade bilíngue pomerano e português brasileiro, cujo bilinguismo nela presente atende à concepção de Couto (2009), segundo a qual, em comunidades com histórias sociais semelhantes, como

\footnotetext{
${ }^{3}$ Na geografia política atual, a Pomerância se localiza entre o nordeste da Alemanha e noroeste da Polônia.
} 
Serra dos Tapes/Santa Augusta, a regra é justamente o bilinguismo, multilinguismo, bidialetalismo e multidialetalismo, em que duas ou mais línguas (em nível interlinguístico), bem como as variedades linguísticas de cada uma (em nível intralinguístico) convivem em um mesmo território e, por isso, podem entrar em contato.

Nesta mesma linha de entendimento, de acordo com a definição de Grosjean (1982), o bilinguismo está presente em praticamente todos os países, em todas as classes sociais, em todos os grupos etários. Não se trata de um fenômeno da língua, mas sim relacionado ao uso, conforme definição de Mackey (1968, p. 555): "uso alternado de duas ou mais línguas por parte de um mesmo indivíduo". O bilinguismo surge, assim, em função das migrações dos povos, os quais levam consigo suas respectivas línguas. Quando eles passam a compor um mesmo território e com isso a interagir por alguma razão, há o contato linguístico (COUTO, 2009; GROSJEAN, 1982); o bilinguismo, portanto, é um fenômeno natural e inevitável das imigrações e do isolamento pelo qual passa o povo migrado com relação ao seu grupo original do qual se desgarrou. Podemos observar a materialização dessas questões na comunidade de Santa Augusta.

Devido ao caráter polissêmico que o bilinguismo assume, estritamente relacionado ao ambiente sociocultural, o sujeito bilíngue é alguém que possui a capacidade de utilizar funcionalmente e de acordo com o contexto mais de uma língua, seja em que grau for. Normalmente, os sujeitos bilíngues usam suas línguas - separadamente ou em conjunto - para diferentes fins, em diferentes domínios, com pessoas diferentes. Eles desenvolveram competências em suas línguas na medida exigida pelas suas necessidades e as do ambiente (GROSJEAN, 1995, p. 259).

No entanto, a partir da perspectiva de Heredia (1989), às situações de bilinguismo subjaz a escolha da língua a ser utilizada, o que por sua vez dependerá dos estatutos, dos papéis, dos lugares e dos sujeitos de conversação. Logo, as regras de uso de uma ou outra língua dentro da comunidade de fala se dão [também] em função das situações sociais. Por isso, em consonância com Fishman (1972), os usos linguísticos são reflexo de complexas relações sociais e de poder dentro da comunidade de fala. Para se compreender como essas questões se dão em Santa Augusta, utiliza-se neste trabalho as noções de diglossia (FERGUSON, 1959; PINHO, 2008) e domínios linguísticos (FISHMAN, 1972). Dessa forma, o primeiro objetivo deste artigo é discutir e entender os usos bilíngues em sua estreita relação com as características socioculturais da comunidade em questão.

Ao analisar a relação entre o bilinguismo e as características socioculturais, chegamos a um ponto importante para a comunidade: o papel da identidade para a manutenção do 
pomerano. O comportamento linguístico, seja em nível individual e/ou de uma comunidade, e o fenômeno da identidade possuem fontes de influência comuns e também são interdependentes. Quando falantes de uma língua se identificam com falantes de outra língua, eles procuram não somente aprender a língua do outro, mas também se ajustar ao padrão de fala de seus interlocutores, provavelmente na tentativa de ajustar, desta forma, diferenças linguísticas e extralinguísticas, mais ou menos ao modo como defendido por Amaral (2015). E o contrário também ocorre, ou seja, quando os falantes de uma língua ou variedade não se identificam com outros, eles tendem a enfatizar as suas diferenças também por meio da linguagem (GUY, 2000; MELLO, 2011). Devido a isso, compreendemos identidade como um fenômeno sociocultural que se constitui na interação linguística.

Para isso, remontamos criticamente ao conceito de identidade da Psicologia Social, enfocando o viés psicossocial dado ao fenômeno pelos franceses Jean-Claude Deschamps e Pascal Moliner (DESCHAMPS; MOLINER, 2014). Desse modo, entendemos que a identidade é constituída nas interações socioculturais, sendo a interação linguística uma delas. A identidade não parte única e exclusivamente do indivíduo para o social e não é simplesmente a fonte de cultura, mas o resultado da cultura, uma vez que é entendida aqui como construção intersubjetiva constituída pela interação capaz de gerar laços associativos entre os indivíduos envolvidos. E a língua (gem), como recurso fundamental para a produção cultural, é, portanto, também um recurso fundamental para a produção de identidade. Logo, língua (gem) é um dos fatores que favorece o estabelecimento da identidade, apontando-nos justamente o movimento contrário, do social para o individual (HALL; BUCHOLTZ, 2004, p. 382; MEY, 1998. p. 69).

No entanto, isso não significa que a identidade seja unicamente resultado do meio. Neste artigo, ela é compreendida como resultado de um processo dinâmico, composto por dimensões socioculturais. Segundo Amaral (2015, p. 57), o esquema ${ }^{4}$ avaliação-orientaçãoidentidade-atitude nos auxilia a compreender: como a avaliação do próprio lugar do indivíduo na comunidade contribui para constituir sua identidade; como consequentemente a orientação dos sujeitos frente a tal posicionamento gera características identitárias; e como suas atitudes refletem sua identidade. Logo, a identidade é constituída pelo tripé sujeito, sociedade e cultura.

\footnotetext{
${ }^{4}$ Os conceitos de Avaliação, Orientação e Atitude, embora não sejam explorados neste texto, tendo em vista o objeto deste trabalho, seguem o que foi estabelecido no âmbito da Sociolinguística e podem ser encontrados em Le Page \& TabouretKeller (1985) [Acts of Identity], Eckert (1989) [Adolescent social structure and the spread of linguistic change] e Haeri (1995) [“Why do women do this?” Sex and gender differences in speech].
} 
Assim, chegamos ao ponto-chave deste artigo: descrever, analisar e compreender a situação de contato linguístico existente na comunidade. Para isso, como já dissemos acima, partimos do pressuposto de que o bilinguismo ali presente é resultado da imigração e, ao mesmo tempo, processo inacabado do arcabouço sociocultural e histórico em que os sujeitos bilíngues estudados estão envolvidos e do qual eles são produtores ativos. Essas relações influenciam, então, a fala em português, de modo que os dados de variação a serem aqui apresentados e discutidos são melhor compreendidos se analisados em sua relação com o espectro bilinguismo, aspectos socioculturais e identidade.

Este artigo baseia-se em estudo qualitativo, de base quantitativa, realizado na Escola Municipal de Ensino Fundamental Martinho Lutero e que gerou a dissertação de mestrado de Mackedanz (2016). Como modelos metodológicos, adaptou-se a Etnografia Antropológica (FINO, 2008; SOUZA; PINTO; ENS, 2004; HALL; BUCHOLTZ, 2004) - que se caracteriza como a descrição de um ou vários aspectos socioculturais de um povo ou grupo social - e foi utilizada a Sociolinguística Variacionista Laboviana, uma vez que os objetivos centrais da pesquisa eram: i) verificar na comunidade de Santa Augusta o papel desempenhado pela língua na construção de padrões identitários ${ }^{5}$ em crianças monolíngues pomerano e/ou bilíngues pomerano/português, ingressantes na vida escolar, bem como em alunos monolíngues português e/ou bilíngues pomerano/português do $9^{\circ}$ ano do ensino fundamental; ii) e, complementarmente, como a identidade - ou o seu processo de construção - influencia a manutenção da língua étnica.

Como objetivos específicos, a pesquisa se propôs também a verificar: (a) de que modo a concepção e tratamento da escola acerca da língua étnica atuou na constituição da identidade em seus alunos do $9^{\circ}$ ano do ensino fundamental; (b) qual a orientação desses alunos com relação à sua comunidade e qual influência isso exerceu na constituição da identidade desses sujeitos; e como esse processo de interlocução se refletiu na e/ou pela língua; (c) se houve marcadores linguísticos da identidade na fala em língua portuguesa dos alunos de $9^{\circ}$ ano do ensino fundamental. Quais eram e como esses fenômenos se relacionaram com a identidade e com a orientação desses indivíduos no que tange à sua comunidade de origem (Sta. Augusta)?; (d) por fim, objetivou-se analisar o papel desempenhado pela identidade no comportamento linguístico de indivíduos monolíngues e bilíngues pomerano/português. Mais especificamente, como a identidade influencia a manutenção da língua étnica. O presente trabalho compartilha os objetivos específicos 'a', 'b', 'c' e 'd'.

\footnotetext{
${ }^{5}$ Ao se falar em "padrões identitários", no plural, faz-se referência aos indivíduos, que juntos constituem um conjunto de padrões identitários, mas que cada sujeito da pesquisa possui sua identidade.
} 
O corpus da pesquisa foi composto por 21 alunos da turma de pré-escolar do ensino fundamental, ingressantes na escola em 2014, a respectiva docente e 29 alunos da turma do $9^{\circ}$ ano também do ensino fundamental, sendo que o foco de nosso trabalho aqui recai sobre a turma de $9^{\circ}$ ano. A Escola Municipal de Ensino Fundamental Martinho Lutero, fundada em 2008, foi escolhida para a pesquisa por desenvolver ocasionalmente atividades que visam à manutenção do pomerano em Santa Augusta, conforme estudos de Mujica (2013).

A coleta dos dados ocorreu em duas etapas, sendo a primeira com a turma de préescolar e a segunda etapa com os jovens do $9^{\circ}$ ano. Durante a primeira etapa, foram observadas aulas, gravada entrevista sociolinguística com a docente e realizou-se levantamento sobre o perfil sociolinguístico das crianças e suas famílias junto à professora e à escola. A segunda etapa foi composta por questionário complementar, preenchido por escrito pelos próprios pesquisados, e gravação em áudio de entrevista sociolinguística semiestruturada e de conversa livre com os alunos do $9^{\circ}$ ano. Neste artigo, enfocamos os dados obtidos através do questionário complementar, das entrevistas sociolinguísticas e da conversa livre. Os primeiros dados nos permitiram trazer elementos sobre a situação do bilinguismo entre os pesquisados e sobre o perfil sociolinguístico dos jovens. Com as entrevistas e conversas livres com cada aluno do $9^{\circ}$ ano, obtivemos aspectos mais específicos quanto às características socioculturais do corpus e os dados de variação do português, os quais foram quantificados. Dados sobre o perfil sociolinguístico da turma de pré-escolar também serão aqui discutidos e atuarão como complementares aos referentes à turma de $9^{\circ}$ ano. Com isso, objetivamos compreender, como um todo, a função do bilinguismo dentro do corpus e sua relação com aspectos socioculturais, com a identidade e com a manutenção do pomerano.

\section{O processo imigratório na Serra dos Tapes}

Nesta seção, discutimos características históricas e geográficas da região e localidade em foco. Objetiva-se com isso trazer um panorama sobre o processo imigratório e, ao mesmo tempo, fatores que possivelmente influenciem os usos bilíngues dos sujeitos pesquisados.

Na geografia política atual da região sul do Rio Grande do Sul, a zona colonial localizada na Serra dos Tapes distribui-se entre os municípios de São Lourenço do Sul, Turuçu, Pelotas, Arroio do Padre, Canguçu, Capão do Leão e Morro Redondo. Santa Augusta localiza-se entre os municípios de Canguçu e São Lourenço do Sul, distante cerca $230 \mathrm{Km}$ da capital gaúcha Porto Alegre. 
Na Serra dos Tapes, o modelo econômico predominante no século XIX baseava-se nas estâncias e charqueadas que constituíam o conjunto da atividade saladeiril. Com isso, os açorianos residentes na região sul passaram a se dedicar mais às atividades pecuárias, o que trouxe muita riqueza para a região, concentrando-se em Pelotas e Rio Grande. RS. Como tal atividade econômica desenvolvia-se mais intensamente em propriedades costeiras, as terras escarpadas da Serra dos Tapes tinham função secundária. Os charqueadores possuíam comumente uma data de mata nessa região e a utilizavam para obter lenha, desenvolver o plantio de lavouras e pomares e para lá eram levados os escravos durante a entressafra. A Serra dos Tapes também servia de esconderijo para os escravos fugidios, pois se constituía como território pouco explorado. Anterior à colonização, a região comportava intensa ocupação indígena, sendo os índios denominados tapes e de tradição tupi-guarani - daí o nome "Serra dos Tapes" (CERQUEIRA, 2010, p. 872).

Na segunda metade do século XIX, desenvolveu-se um movimento sistemático de criação de colônias imigratórias na região. Segundo Cerqueira (2010, p. 872), tal movimento era diverso do urbano, ocorrendo, nesse sentido, de forma espontânea. Em decorrência da necessidade de ocupação da Serra dos Tapes com mão de obra agrícola, surgiu uma "nova frente de investimentos: a criação de colônias por particulares”. Em 1849, iniciou-se um processo de colonização por meio da imigração de europeus. Com isso, o governo imperial viu nos imigrantes europeus uma forma de ocupação territorial e desenvolvimento da agricultura na Serra dos Tapes (SALAMONI et. al., 1995).

Foram criadas entre 1849 e 1850 as primeiras colônias particulares, mas foi em janeiro de 1858 que essa frente de investimentos ganhou impulso, por meio da criação da Colônia Rheingantz, na atual região de São Lourenço do Sul, pelo então empresário renano Jakob Rheingantz. Em 1856, Rheingantz firmou com o Governo Imperial um contrato de colonização, sendo que este vendeu para Jakob oito léguas quadradas de terras devolutas na Serra dos Tapes. E em outubro de 1857, aproximadamente, embarcou na Alemanha a primeira leva de imigrantes germânicos, em sua maioria pomeranos, composta por 88 indivíduos, os quais chegaram ao Brasil em janeiro do ano seguinte. Os lotes de terras demarcados por Jakob eram vendidos aos colonos, proporcionando com isso grandes lucros ao empresário e ao seu sócio, Sr. José Antônio de Oliveira Guimarães (WILLE, 2011; THUM, 2009; CERQUEIRA, 2010). 
A Pomerânia ${ }^{6}$, por sua vez, era uma região essencialmente agrícola, com terras planas e presença de muitos lagos e rios. As principais atividades produtivas eram a pesca e a agricultura, o que mais tarde contribuiria para a formação e desenvolvimento da colônia na Serra dos Tapes (MALTZAHN, 2010). Além disso, o território da Pomerânia era segmentado em grandes latifúndios, nos quais os pequenos agricultores viviam, porém, em condições miseráveis e eram associados aos "barões", proprietários das terras, para quem produziam (BORGES, 2004). Dessa forma, a busca por melhores perspectivas futuras, entre elas viver sem guerras e sem fome, impulsionou os pomeranos a imigrarem para o Brasil, um país jovem, com uma imagem de terra de fartura.

Ao chegaram à colônia de São Lourenço, os imigrantes se depararam com várias condições adversas. Eles precisaram abrir picadas em matas fechadas, construir moradias e estradas, o que fez com que permanecessem isolados em suas porções de terra, trabalhando na agricultura para o próprio consumo e com mão-de-obra familiar. Por esses motivos, segundo Maltzahn (2010), os pomeranos passaram a constituir famílias numerosas, com cerca de 10 ou 12 filhos por casal, justamente no intuito de obterem maior mão-de-obra para o trabalho na lavoura. Uma família numerosa passou a ser símbolo de prosperidade, de modo que "os pomeranos valorizam até os dias de hoje o trabalho e a família" (MALTZAHN, 2010: 906), sendo inclusive de suma importância que os jovens, desde cedo, aprendam a lida na lavoura, para que possam ajudar seus pais e, assim, perpetuar o trabalho na propriedade.

A maneira como o trabalho familiar agrícola foi e ainda é desenvolvido entre os pomeranos na Serra dos Tapes pode ser compreendido, em um primeiro momento, como resultado da necessidade de adaptação nas novas terras. Por outro lado, ao longo da expansão da agricultura familiar, aspectos entendidos como históricos se tornaram também características socioculturais. Desse modo, famílias numerosas e a manutenção do poderio agrícola entre os filhos, através do ensinamento aos jovens de como deve ser realizado o trabalho rural, configuram-se como aspectos que possivelmente influenciam o fenômeno do bilinguismo entre os pesquisados e também a variação linguística do português brasileiro na fala do grupo pesquisado em Santa Augusta. Assim, a partir da discussão acima, realizamos, na seção a seguir, a inter-relação entre fatores socioculturais e os usos linguísticos.

\footnotetext{
${ }^{6}$ Pomerânia se situava nas costas do mar Báltico, entre os atuais países da Alemanha, Polônia e países escandinavos. O nome Pomerânia, forma latinizada para Pommern, origina-se do correspondente eslavo Po Morje, que significa "os que habitam ao longo do mar" (WILLE, 2011).
} 


\section{O bilinguismo em Santa Augusta}

Para compreendermos o significado do bilinguismo elucidamos as características socioculturais do grupo em foco. Complementarmente ao exposto na seção anterior, trazemos aqui aspectos mais específicos, como escolaridade, religião e ocupação profissional, os quais se mostraram como que relacionados à constituição identitária dos pesquisados.

A maioria dos pais dos jovens pesquisados é agricultor, sendo, nesse sentido, a agricultura familiar de subsistência a principal atividade econômica das propriedades rurais, conforme excerto abaixo extraído de entrevista sociolinguística com informante da turma de $9^{\circ}$ ano:

[Plantamos] milho, fumo, batata, feijão (...). O milho e as batatas plantamos só pro nosso próprio consumo. Só o fumo que nós vendemos (...). Animais sempre têm. Fruta também (...), bergamota, laranja, pêssego. (...) Tem galinha, pato, marreco, ganso, boi, vaca. (Informante 22, masculino)

Produtos como tabaco, milho e soja são cultivados para serem comercializados e geram a maior parte da renda da família. Hortaliças, frutas e criação de animais são usadas principalmente para o próprio consumo, sendo em alguns casos vendidos nos comércios locais e entre os próprios moradores.

No que diz respeito à religião, segundo Salamoni et. al. (1995), os colonos pomeranos trazidos por Jacob Rheingantz eram culturalmente religiosos, protestantes ou católicos, o que, atualmente, parece se manter, segundo os dados abaixo. Chegando ao Brasil, eles tratavam de construir igrejas em suas comunidades. $\mathrm{O}$ isolamento em relação ao meio urbano, as diferenças de idioma, acompanhado das dificuldades em conseguirem padres/pastores e materiais religiosos fizeram com que os pomeranos adotassem a religião protestante (SALAMONI, et. al., 1995). Das 50 famílias participantes da pesquisa, uma é católica, porém a maioria frequenta a Igreja Evangélica Livre (22 famílias); 14 famílias frequentam a Igreja Evangélica de Confissão Luterana no Brasil (IECLB), 10 famílias, a Igreja Evangélica Luterana do Brasil (IELB) e 3 são da Igreja Evangélica Independente. E quanto à escolaridade, a maioria dos pais possui ensino fundamental incompleto; cinco pais possuem ensino fundamental completo e três, ensino médio completo.

Como está demonstrado no gráfico abaixo, e com a devida observação de que o total de informantes é relativamente baixo para conclusões mais definitivas, chama a atenção o percentual de sujeitos bilíngues pomerano e português brasileiro na comunidade. 


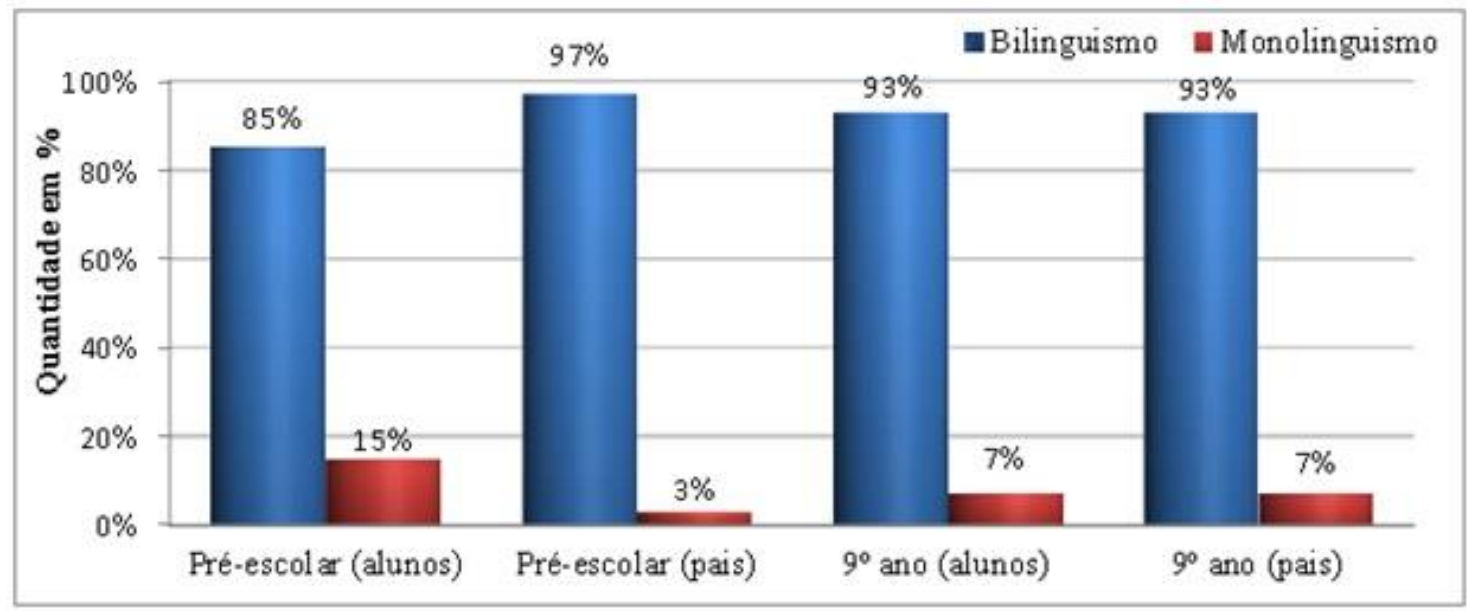

Figura 01 - Bilinguismo e Monolinguismo (português) dos alunos e respectivos pais

Apenas como forma de ilustrar o mapa do bilinguismo na comunidade, os valores a seguir dão indícios de como os informantes se veem, já que dezoito das vinte e uma crianças (pré-escolar) e vinte e sete dos vinte e nove jovens ( $9^{\circ}$ ano) responderam ao questionário que falam pomerano, o que aponta a presença e uso frequente da língua étnica. Além disso, cinco pais mencionaram não falar pomerano e, no caso das crianças da turma de pré-escolar, segundo testemunho da professora, seis ingressaram na escola em 2014 como monolíngues em pomerano e doze como bilíngues. Com isso, os dados apontam que a língua étnica possui prestígio entre os pesquisados.

Porém, o gráfico 1 indica, por um lado, queda no bilinguismo de 93\% (jovens) para $85 \%$ (crianças) e, por outro, aumento de $7 \%$ (jovens) para 15\% (crianças) quanto à quantidade de alunos monolíngues em português. Analisando esses dados de uma perspectiva temporal, ambos os grupos podem ser entendidos como duas extremidades de determinado evento de fala, o qual, desse modo, é caracterizado pelo maior espaço que o português brasileiro pode estar ganhando entre os usos linguísticos dos informantes e, em uma perspectiva mais ampla, da comunidade.

Ainda que existam indícios de um uso crescente do português, o prestígio do pomerano é mais bem compreendido em sua relação com os domínios de uso das línguas, especialmente no domínio do lar e no cotidiano do trabalho agrícola. Em 14 das 21 famílias (pré-escolar) e em 23 das 29 famílias ( $9^{\circ}$ ano), a língua mais utilizada no lar é o pomerano: 


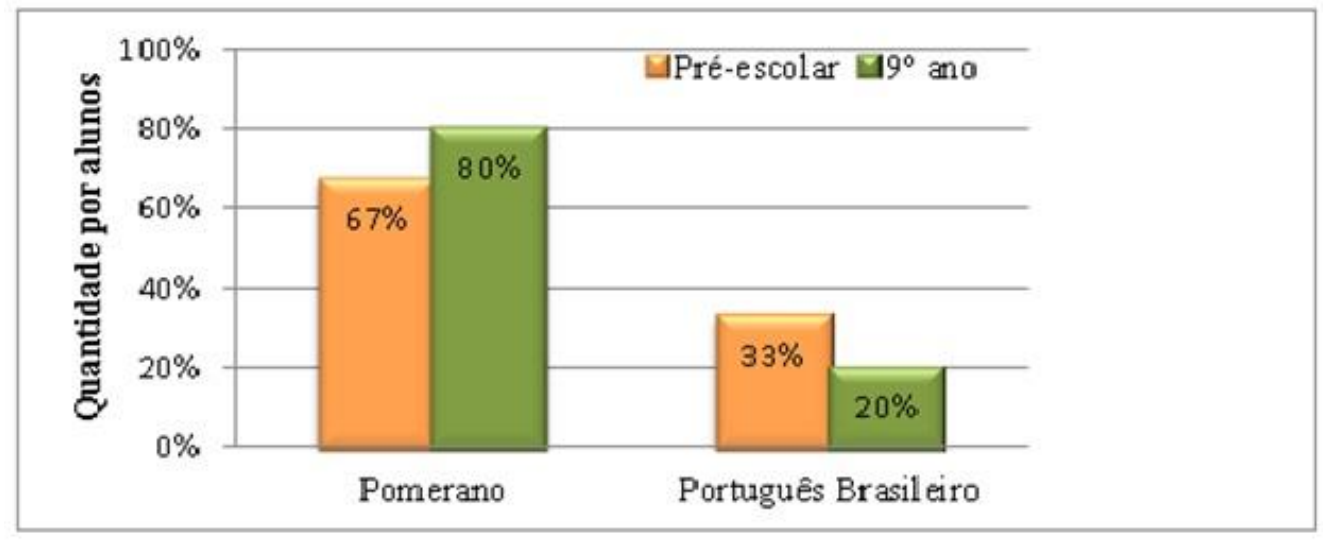

Figura $02^{7}$ - Língua mais falada no lar

A partir dos dados, podemos observar que a família desempenha importante papel para a manutenção da língua étnica (SILVA, 2011; FISHMAN, 1972). É no lar, com os pais, tios e avós que a língua étnica é empregada. Segundo Fishman (1972), como instituição, a família cria e mantém limites que podem evitar o avanço da língua majoritária, em nosso caso, o português. Em Santa Augusta, o uso do pomerano no lar configura uma característica sociocultural transmitida entre as gerações: Os pais também sempre falaram com nós em pomerano. Ensinaram que nós devemos falar em casa pomerano ${ }^{8}$. (Informante 28, masculino).

As relações socioculturais dentro do núcleo familiar e agrícola dos pomeranos em Santa Augusta determinam e são determinadas pelo fenômeno do bilinguismo, como está demonstrado no gráfico a seguir. O uso do português ocorre tanto no lar como na lavoura. Porém, a manutenção do alto grau de bilinguismo - com mais de $80 \%$ de sujeitos bilíngues e, principalmente, a manutenção do pomerano se dá pelo significado sociocultural que a língua étnica possui, especialmente, nesses dois domínios: lar e lavoura.

\footnotetext{
${ }^{7}$ Dados extraídos do questionário complementar, questão 14: qual língua é mais falada em casa?.

${ }^{8}$ Resposta à pergunta 5 da entrevista sociolinguística com alunos do $9^{\circ}$ ano: tu ajudas na lavoura elou nos afazeres de casa? Por que?
} 


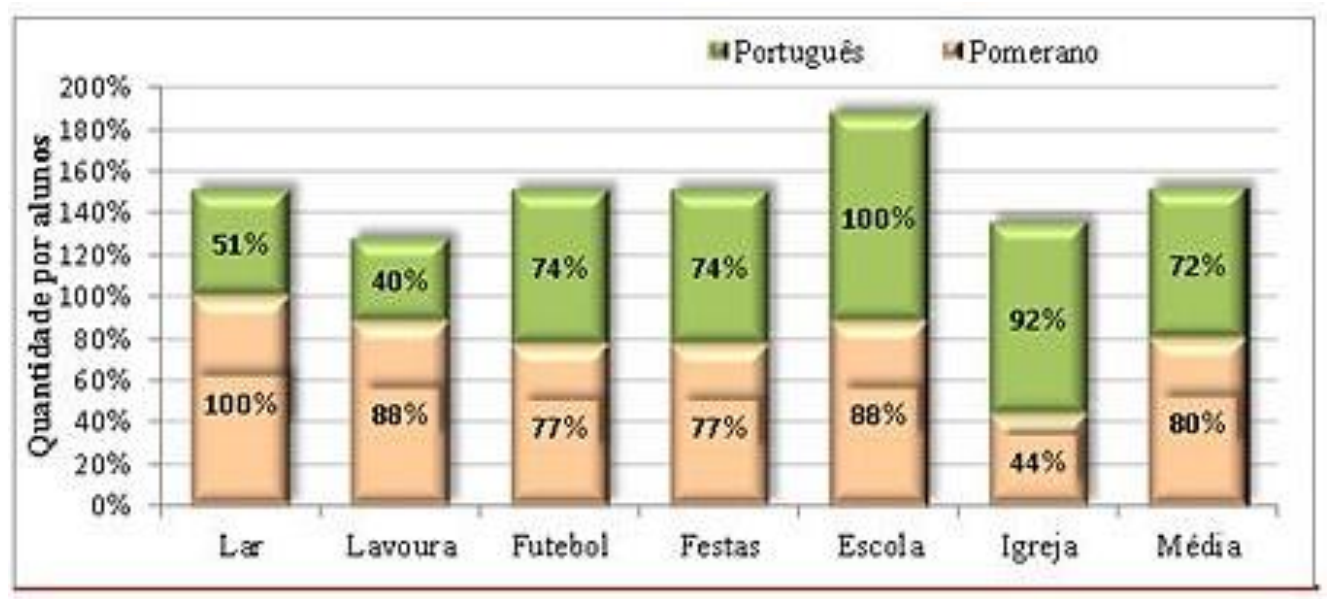

Figura 03 ${ }^{9}$ : Domínios Linguísticos ${ }^{10}$ (do informal ao formal): alunos bilíngues pomerano e PB $\left(9^{\circ}\right.$ ano)

Na maioria dos domínios, parte significativa (próximo a 80\%) dos jovens afirma usar o pomerano. Mas é no lar, na lavoura e na escola que há os maiores percentuais, chegando a 100\%. O pomerano é a língua familiar, do lar e, concomitantemente, do trabalho em família na lavoura É nesse aspecto sociocultural que reside o valor identitário do pomerano.

$\mathrm{Na}$ configuração cotidiana do trabalho familiar na lavoura, às mulheres competem as tarefas de cuidado do lar e dos filhos, como preparar a comida, lavar roupas, cuidar da casa e também auxiliar nas atividades agrícolas. O homem realiza as atividades mais ligadas ao trabalho com a terra e com os implementos agrícolas, como o trator (MALTZAHN, 2010; SALAMONI et. al., 1995). "Eu, meu pai, minha mãe, meu tio, minha vó, aí minha tia [vamos pra lavoura]. (...) Só que agora aquela tem que cuidar o filho dela também. Mas aquela também (...) cuida do almoço e das coisas tudo assim. (...)” (Informante 04, masculino)

Os jovens, por sua vez, são educados desde cedo pelos pais a auxiliarem nas tarefas de casa e na lavoura, o que, além de reforçar a importância do trabalho em família para a agricultura em Santa Augusta, evidencia o papel social que homem e mulher possuem dentro da família e da comunidade. “(...) O meu irmão é mais novo, homem. Com certeza ele iria ajudar mais o pai. Daí eu sou menina, eu ajudo a mãe em casa. (Informante 08, feminino ${ }^{11}$ ). Devido à sua faixa etária, os jovens já possuem tarefas bem delimitadas dentro da organização familiar. As meninas são responsáveis principalmente pelo cuidado com a casa e não auxiliam

\footnotetext{
${ }^{9}$ Dados extraídos do questionário complementar, parte II, questões 17 (Em que ambientes tu falas em pomerano?) e 20 (Em que ambientes tu falas em português?). Os alunos poderiam marcar com um X quantos domínios julgassem necessários, em ambas as questões.

${ }^{10}$ A escolha dos domínios se deu em conformidade com os aspectos sociais e culturais de Santa Augusta. Aos finais de semana, as festas religiosas e os campeonatos de futebol na região são comuns. Os cultos religiosos também fazem parte da rotina dos pomeranos, especialmente aos domingos.

${ }^{11}$ Resposta retirada de entrevista sociolinguística, questão 4: quem da tua família vai para a lavoura? Quem costuma ficar em casa e fazer o almoço?
} 
tanto na lavoura, estando, por isso, mais ao lado de suas mães durante as atividades. Já os meninos acompanham mais o pai nas tarefas com a terra.

O uso do pomerano, conforme o gráfico 3 acima, também se mostra alto no domínio da escola (88\%), pois sua utilização é incentivada em todos os ambientes da escola; além disso, a E.M.E.F. Martinho Lutero desenvolve ocasionalmente ações em prol da valorização e manutenção da língua étnica, como a confecção de cartazes bilíngues a serem expostos na escola, peças teatrais em pomerano e palestras sobre a língua para a comunidade escolar. Ainda assim, há o uso majoritário do português, devido ao fato de a escola estar historicamente associada ao ensino do português brasileiro em sua forma padrão (CARVALHO, 2010): “[...] Aqui na escola, a gente tem que falar português [...]” (informante 11, feminino).

Segundo Ferguson (1959), a língua oficial (neste caso o português) detém maior prestígio entre os falantes e tem capacidade de instaurar "poder". Por esse motivo, podemos compreender o papel que o PB assume no domínio da igreja, de modo que é a língua que ganha mais espaço, devido justamente ao seu prestígio. Já em ambientes informais, ou seja, nos campeonatos de futebol, característicos na região por ocorrerem em todos os finais de semana e comportarem número significativo de pessoas, assim como nas festas religiosas, igualmente frequentes e populosas em Santa Augusta e em seu entorno, não há distinção quanto aos usos bilíngues (o percentual de alunos que usam as línguas é igual). Desse modo, como configuração linguística, os dados apontam que o pomerano predomina no lar, seu uso parece equilibrado nos domínios de campeonatos de futebol e nas festas comunitárias, há um leve predomínio do PB na escola, porém o português predomina na igreja.

$\mathrm{O}$ alto índice de bilinguismo, e mais precisamente, o uso expressivo do pomerano no lar e na lavoura parecem refletir, desse modo, os valores familiares e agrícolas das famílias pesquisadas, os quais são passados entre as gerações. Mais precisamente, ao preferirem o pomerano no lar e na lavoura, conforme figura 3, as famílias usam a língua para se identificarem como grupo; conforme os dados, é em pomerano que ocorre a maior parte das conversas cotidianas sobre, por exemplo, como realizar as atividades da lavoura e quais membros o farão, uma vez que a base econômica da localidade reside na agricultura familiar. Inclusive, a imigração parece ter contribuído de modo determinante para tal organização linguística e sociocultural, uma vez que o trabalho em família representa justamente união e prosperidade, especialmente após a chegada dos imigrantes ao Brasil (MALTZAHN, 2010).

Diante disso, então, a identidade, entendida em sua relação com as características linguísticas e socioculturais do corpus, mostra-se como que relacionada ao bilinguismo, bem 
como parece desempenhar importante papel para a manutenção do pomerano, pois representa os valores familiares dos pomeranos. E a língua, o pomerano, é constitutiva da identidade desses indivíduos, pois é a língua mais utilizada nos domínios do lar e da lavoura.

\section{A influência do bilinguismo nos fenômenos de variação}

Na seção anterior, vimos características socioculturais da comunidade e a situação de bilinguismo nela presente. Voltemos aqui à escolaridade. Conforme elucidado, a maioria dos pais possui ensino fundamental incompleto. No caso da turma de $9^{\circ}$ ano, tal configuração justifica o desejo dos pais para que seus filhos continuem os estudos após a conclusão do ensino fundamental, conforme informante 8 (feminino): “[Meus pais acham que eu deveria] continuar os estudos. (...) Eles querem que eu tenha um futuro melhor do que o deles (...). Eles não estudaram tanto. (...)”

A atividade agrícola é caracterizada como que deixando de ser rentável aos colonos e, por isso, os pais dos alunos também apoiam para que seus filhos continuem os estudos e não dependam futuramente única e exclusivamente da lavoura: "É que ele [o pai] fala que a vida na lavoura não é muito boa (...). É tudo muito caro, os insumos. (Informante 11, feminino.)

"No meu caso, [...] eu queria não estudar mais. Mas o meu pai [...] e minha mãe [...] queriam que eu estudasse, [...] pra ter uma vida melhor depois. Não se matar trabalhando." (Informante 6, masculino.)

Obter maior escolaridade é algo que possui valor para os pais dos jovens pesquisados. No entanto, enquanto que a maioria das meninas deseja sair da comunidade para conseguir um emprego e realizar um curso superior, a maior parte dos meninos exibe a tendência de permanência na comunidade, ainda que eles concluam o ensino médio. 15 dos 21 informantes do gênero masculino desejam permanecer na comunidade. Há também indícios de que os pais apoiam os meninos para que obtenham maior escolaridade, no caso, o ensino médio, porém permanecendo na comunidade e continuando com as atividades agrícolas da família: "eu acho que, na opinião deles, [eu deveria] completar o ensino médio e depois continuar na lavoura." (Informante 21, masculino)

Nas entrevistas sociolinguísticas, observamos que os usos linguísticos em português dos alunos bilíngues do $9^{\circ}$ ano relacionam-se com a orientação desses jovens, isto é, se eles desejam permanecer na comunidade e trabalhar na agricultura ou se optam por futuramente 
deixar Santa Augusta, continuar os estudos para além do ensino médio e desempenhar outra atividade. Os seguintes excertos de duas entrevistas sociolinguísticas elucidam tal ponto:

ENTREVISTADORA: E como tu te imaginas daqui a vinte anos?

Indo embora daqui. Eu quero morar na cidade. [...] Eu quero ter um bom emprego, pra, se um dia eu tiver filhos, dar um futuro melhor. (Informante 09, feminino)

Eu me imagino na colônia. [...] Na agricultura, plantando fumo e soja [...]. (Informante 21, masculino)

Há marcas linguísticas no português falado pelos jovens bilíngues que podem estar associados a influências linguísticas do pomerano e ser reveladores de uma orientação para dentro da comunidade. Traços prosódico, fonético-fonológico e morfológico distintos da variedade padrão do PB foram encontrados na fala desses jovens. Destacamos aqui os traços fonético-fonológicos, por terem ocorrido com maior número de realizações. São eles: a líquida lateral alveolar como em [alguma] e [difícil]; e o tepe como em [caro] e [responder]. Porém, a variante vocalizada [w], como em [facuwdade] e [finaw], assim como a variante fricativa [R], como em [caRinho] e [Ruim], também ocorreram.

As realizações dos fenômenos são influenciadas pela orientação dos jovens (para dentro ou para fora da comunidade, conforme Amaral (2015) e pelos papeis sociais distintos e bem marcados que homem e mulher parecem possuir. A fala das meninas se aproxima da variante padrão e urbana do $\mathrm{PB}$, pois os 8 indivíduos do gênero feminino usam preferencialmente $[\mathrm{w}]$ e $[\mathrm{R}]$, enquanto que os 21 meninos preferem as formas mais distantes da variante padrão do PB; logo, eles exibem em sua fala número maior de realizações para [1] e [r], conforme figura abaixo:

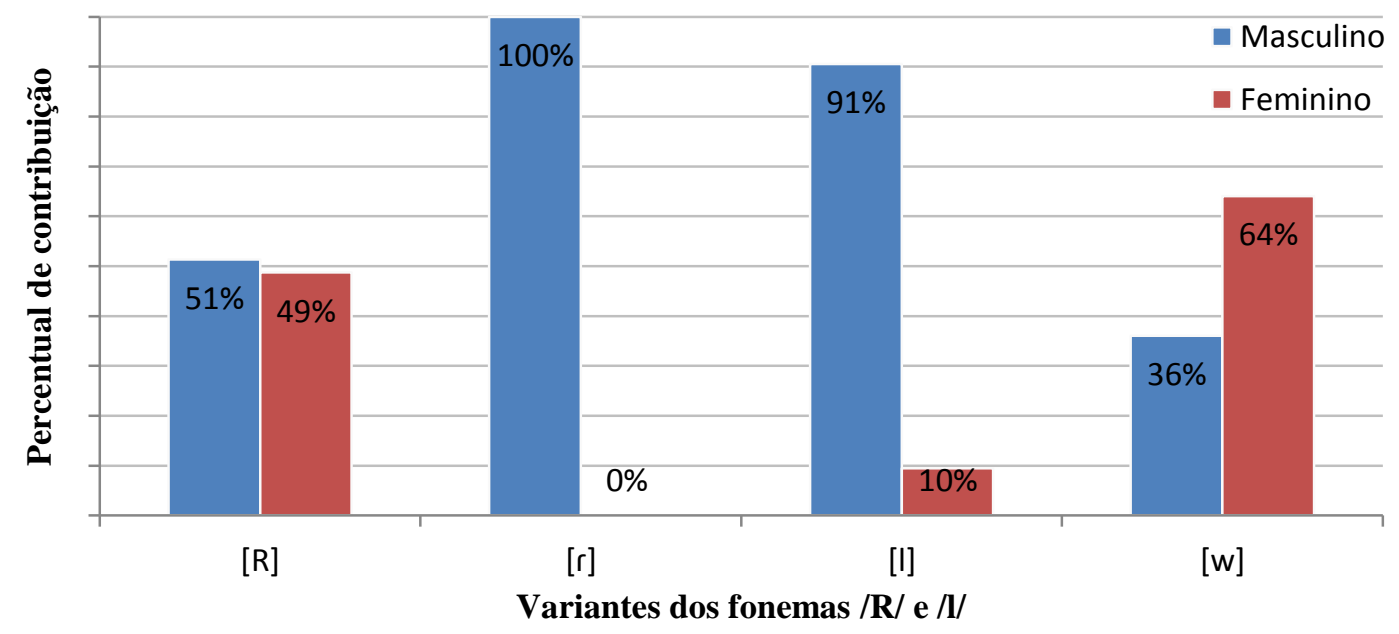

Figura 04 - Percentual de contribuição de cada gênero por variante dos fonemas /R/ e /l/ 
Há uma inversão entre meninos e meninas. Para [w], dentre todas as 147 possibilidades de realização, os indivíduos do gênero feminino apresentam maior percentual de contribuição (64\%). Para [R], há pequena diferença entre os gêneros. Para [r] e [1], os meninos possuem percentual maior de contribuição, chegando a $100 \%$ para o tepe. Desse modo, as formas características do $\mathrm{PB}$ padrão, $[\mathrm{R}] \mathrm{e}[\mathrm{w}]$, são variantes linguísticas que podem sugerir identidade da fala dos sujeitos do gênero feminino. O mesmo ocorre com [r] e [1], que se mostram como indícios da existência de transferências do pomerano para a fala em português e de marcadores linguísticos da fala dos sujeitos do gênero masculino. Os papeis associados a gênero, por nós entendidos como características socioculturais, parecem influenciar não só a manutenção do pomerano e, consequentemente, o grau de bilinguismo da comunidade, como também a fala em PB dos sujeitos bilíngues pomerano e português.

Inter-relacionada a essas questões, está a orientação dos jovens. São os jovens que desejam permanecer em Santa Augusta, que apresentam em sua fala em PB maior quantidade de índices linguísticos reveladores de identidade, no caso maior realização das variantes [r] e [1], conforme gráfico abaixo:

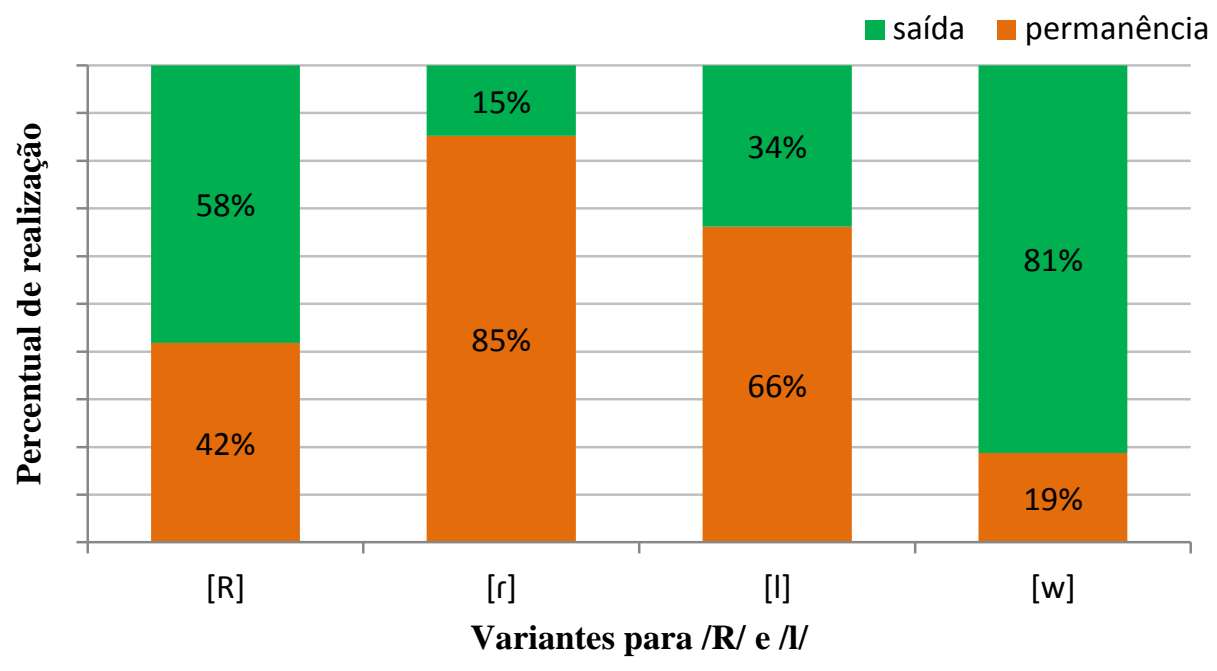

Figura 05 - Percentual de uso dos fonemas /R/ e /1/ segundo a orientação

Uma comparação do que está demonstrado nas figuras 4 e 5 revela a possível associação entre a taxa de uso de [r] e uma orientação para dentro da comunidade, ou pelo menos, com as atividades relacionadas ao trabalho na lavoura. Aqui são os indivíduos que desejam permanecer em Santa Augusta que mais realizações para [r] e [1] possuem. Além disso, todos os 15 jovens com orientação para dentro da comunidade são do gênero masculino. $\mathrm{O}$ mesmo ocorre com relação aos 12 informantes que desejam sair de Santa Augusta, dos quais 7 são do gênero 
feminino. Estas preferem as variantes [R], com 64 realizações $(58,2 \%)$ de 110 possíveis, e a forma vocalizada [w], com 118 realizações $(81,3 \%)$ de 145 possíveis.

Há que se mencionar que, dentre os informantes masculinos, houve meninos que desejam permanecer na comunidade, continuar como agricultores e que utilizam preferencialmente o tepe [r] e a alveolar [1]: "Agora eu vou ficar em casa, [...] seguindo na roça, trabalhando com o que mais gosto. [...] Como o pai agora, seguir a coisa dele." (Informante 22, masculino); e há aqueles que se veem em uma atividade distinta da agricultura, como caminhoneiro, mecânico, comerciário: “[...] Eu quero ser mecânico [...] Eu pretendo ficar aqui, ter a minha família. ” (Informante 25, masculino).

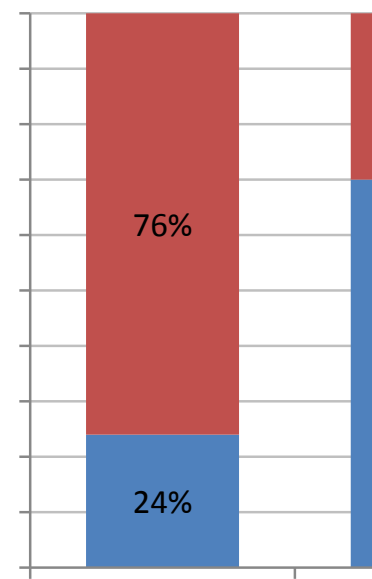

$[R]$

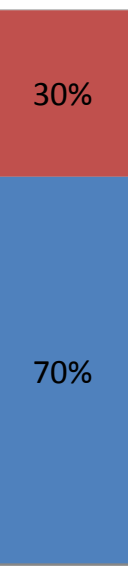

[r]

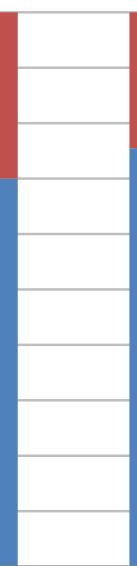

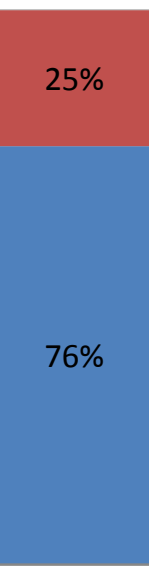

[l]

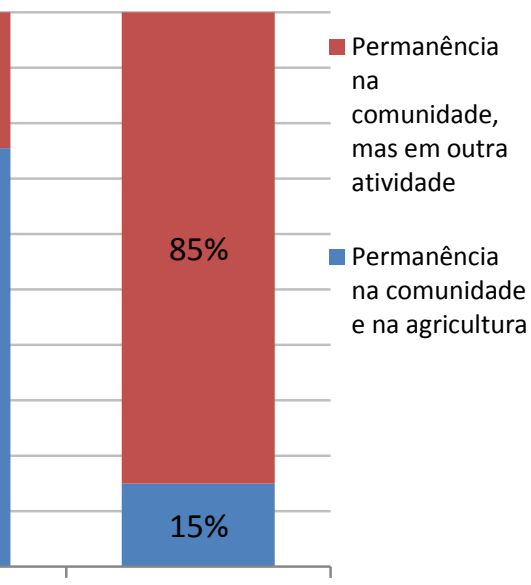

$[w]$

Figura 06 - Desejo de continuar (ou não) com as atividades agrícolas (informantes com orientação para dentro da comunidade)

Há nessa figura uma inversão quanto à realização das variantes. Enquanto o grupo 1 apresenta maior ocorrência das formas padrão do PB, o grupo 2 tende a usar as formas associadas à transferência linguística.

Diante do exposto, os usos linguísticos em PB dos jovens parecem refletir e, ao mesmo tempo, determinar a relação entre gênero, respectivos papeis sociais e a orientação dos indivíduos, assim como a identidade é constituída pela relação bilinguismo e aspectos socioculturais. As meninas, ao desejarem continuar seus estudos, se distanciam das atividades agrícolas em família e, de certo modo, do papel social que a mulher detém na organização familiar pomerana. Além desses aspectos, as meninas demonstram um interesse maior pelos estudos. Alguns meninos, por sua vez, afirmam não gostar de estudar, não conseguir, e por isso seu interesse seja menor, conforme seguinte excerto: "Por um lado é melhor [...] pro meu futuro [seguir estudando]. Mas, às vezes, eu não gosto de estudar essas coisas. [...] Eu gosto mais de ir na lavoura. " (Informante 20, masculino.) 
As diferenças entre os grupos - figura 06 - para as realizações das formas padrão e não padrão dos fonemas /R/ e /l/ parecem ser indícios de que o uso do tepe [r] e da alveolar [1] pode estar ligado aos valores familiares dos pomeranos, assim como o uso do pomerano nos domínios do lar e da lavoura. A identidade desses jovens, nesse sentido, pode estar constituída pela relação entre orientação, gênero e papeis sociais desempenhados pelo homem e pela mulher na família pomerana. Desse modo, então, o uso do tepe e da alveolar por parte dos jovens do grupo 2 pode ser entendido como ato identitário desencadeado pelo fenômeno do bilinguismo pomerano/português, ainda fortemente presente em Santa Augusta.

\section{Considerações finais}

Os dados aqui discutidos apontam que o bilinguismo presente no grupo pesquisado da comunidade pomerana de Santa Augusta relaciona-se com a manutenção do pomerano, com a variação na fala em português brasileiro dos sujeitos bilíngues e, principalmente, com a constituição da identidade. Além disso, pode ser entendido como pressuposto fundamental para a compreensão das relações socioculturais existentes na comunidade. Por esse motivo, há indicativos de que o bilinguismo não se apresenta apenas como fenômeno linguístico, como também, e principalmente, característica sociocultural, importante para a compreensão dos processos históricos, sociais, culturais e linguísticos subjacentes ao contexto de imigração da Serra dos Tapes.

O fato de o PB ser a língua oficial do país e por isso detém maior prestígio no cenário linguístico brasileiro pode configurar em um importante ponto de influência que ajude a explicar se o alto índice de bilinguismo da comunidade irá se manter. Não há estudos anteriores de caráter histórico, indicando que o pomerano sempre foi a língua mais falada em Santa Augusta. A pesquisa apontou, sim, alto índice de manutenção do pomerano. Desse modo, então, ao que tudo indica, o pomerano se manterá enquanto a organização social da comunidade estiver centrada na lavoura, domínio no qual a língua pomerana é pujante.

\section{REFERÊNCIAS}

ALTENHOFEN, C. V.; RASO, T.; MELlO, H. Os contatos linguísticos e o Brasil. Dinâmicas pré-históricas, históricas e sociopolíticas. In: MELLO, H.; ALTENHOFEN, C.; RASO, T. Os contatos linguísticos no Brasil. Belo Horizonte: Editora UFMG, 2011. 
AMARAL, L. I. C.. Marcadores linguísticos de gênero e sua relação com a adesão escolar de meninos impúberes. In: Identidade Social e Contato Linguístico no Português Brasileiro. Rio de Janeiro: EDUERJ, 2015, p. 37-71.

BORELLA, S. G. A produção oral das oclusivas de falantes bilíngues hunsriqueanoportuguês na leitura do português. In: Letrônica, Porto Alegre, v. 7, n. 2, p. 569-587, jul./dez., 2014.

BORGES, P. R. S. Análise histórico-social-linguística de quatro famílias da comunidade pomerana da região de Pelotas/RS. Pelotas: Caderno de Letras (UFPel), v. 1, n. 10, p. 191211, 2004.

BÖTTNER, Markus. Varieties as the Starting Point of Second Language Acquisition: Focus on Irish English in Teaching and Learning German. In: HENNEMANN, Anja; SCHLAAK, Claudia (Hg.). Korpuslinguistische Untersuchunge: Analysen einzelsprachlicher Phänomene. Berlin: Frank \& Time, 2013, p. 175-185.

CARVALHO, A. M. Contribuições sociolinguísticas ao ensino do português em comunidades bilíngues do norte do Uruguai. Pro-posições. Campinas, v. 21, n. 3 (63), set/dez 2010.

CERQUEIRA, F. V. Serra dos Tapes: mosaico de tradições étnicas e paisagens culturais. In: Anais do IV Seminário Internacional em Memória e Patrimônio. Universidade Federal de Pelotas, 872-962, 2010. Disponível em: <http://simpufpel.files.wordpress.com/2010/09/mesaserra-dos-tapes.pdf>. Acesso em 13 de dez. de 2014.

COUTO, H. H. Conceituando contato de línguas. In: COUTO, H. H. Linguística, ecologia e ecolinguística - Contato de línguas. São Paulo: Contexto, p. 49-60, 2009.

DESCHAMPS, J. C.; MOLINER, P. A identidade em Psicologia Social: dos processos identitários às representações sociais. 2. ed. Tradução de Lúcia M. Endlich Orth. Petrópolis: Vozes, 2014.

ECKERT, P. The hole woman: sex and gender diferences in variation. Language Variation and Change, Cambridge, n. 1, p. 245-67, 1989.

FERGUSON, C. A. Diglossia. Word. Journal of linguiistic 15, v. 1, p. 325-340, 1959.

FINO, C. N. A etnografia enquanto método: um modo de entender as culturas (escolares) locais. In: Christine Escallier e Nelson Veríssimo (Org.) Educação e Cultura. Portugal: Funchal, DCE - Universidade da Madeira, p. 43-53, 2008. Disponível em: <http://www3.uma.pt/carlosfino/publicacoes/22.pdf>. Acesso em: 30 de maio de 2014.

FISHMAN, J.A. The Relationship between Micro- and Macro-Sociolinguistics in the Study of Who Speaks What Language to Whom and When. In: PRIDE, J.B. \& HOLMES, J. (eds.). Sociolinguistics. Harmondsworth: Pinguim Books, 1972, p. 15-32.

GROSJEAN, F. Life with two languages. An introduction to Bilingualism. England: Harvard University Press, 1982.

GROSJEAN, F. A psycholinguistic approach to code-switching: the recognition of guest words by bilinguals. In: MILROY, L.; MUYSKEN, P. One speaker, two languages. Nova York: Cambridge University Press, 1995, p. 259-275.

GUY, Gregory R. A identidade linguística da comunidade de fala: paralelismo interdialetal nos padrões de variação linguística. Organon, v. 14; n. 28-29, 2000.

HAERI, N. "Why do women do this?" Sex and gender differences in speech. In.: GUY, G. et al. (eds.) Towards a Social Science of Language. v. 1. Philadelphia: John Benjamins, 1995, p. 101-14.

HALL, K.; BUCHOLTZ, M. Language and Identity. In: DURANTI, A. A Companion to Linguistic Anthropology. USA: Blackwell Publishing, 2004, cap. 16, p. 369-394.

HEREDIA, C. Do bilinguismo ao falar bilíngue. In: VERMES, G.; BOUTET, J. (orgs.). Multilinguismo. Campinas: Ed. da UNICAMP, 1989.

LE PAGE, R. B. \& TABOURET KELLER, A. Acts of identity: creole-based approaches to language and ethnicity. Londres: Cambridge University Press, 1985. 
MACKEY, W. F. The Description of Bilingualism. In: FISHMAN, J.A. Readings in the Sociology oj Language. The Hague: Mouton, 1968.

MALTZAHN, G. M. Memórias Míticas: uma proposta de análise sobre as narrativas orais dos descendentes pomeranos da Serra dos Tapes/RS. In: Anais do IV Seminário Internacional em Memória e Patrimônio. Universidade Federal de Pelotas, p. 905-915, 2010. Disponível em: $<$ http://simpufpel.files.wordpress.com/2010/09/mesa-serra-dos-tapes.pdf $>$. Acesso em $13 \mathrm{de}$ dezembro de 2014.

MELlO, H. A. B. Prefácio. In: SILVA, Sidney de Souza (Org.). Línguas em Contato: cenários de Bilinguismo no Brasil. São Paulo: Ed. Pontes, 2011, p. 9-13.

MEY, J. L. Etnia, identidade e língua. In: SIGNORINI, Inês (Org.). Língua(gem) e Identidade - elementos para uma discussão no campo aplicado. Campinas, SP: Mercado das Letras, 1998, p. 69-88.

MORELLO, R. (org.). Leis e línguas no Brasil. O processo de cooficialização e suas potencialidades. Florianópolis: IPOL: Nova Letra, 2015, 140p.

MUJICA, M. M. Atitude, orientação e identidade linguística dos pomeranos residentes na comunidade de Santa Augusta- São Lourenço do Sul-RS- Brasil. 90f. 2013. Dissertação (Mestrado) - Programa de Pós-Graduação em Letras. Universidade Federal de Pelotas.

PINHO, I. C. Diversidade e Identidade: as micro-decisões na manutenção/perda de uma língua materna minoritária. In: Revista Contingentia: Universidade Federal do Rio Grande do Sul, v. 3, n. 1, 2008. Disponível em: <http://seer.ufrgs.br/contingentia/article/view/4159>. Acesso em: 23 de maio de 2013.

PUPP SPINASSÉ, K. Os conceitos de língua materna, segunda língua e língua estrangeira e os falantes de línguas alóctones minoritárias no Sul do Brasil. In: Revista Contingentia. Porto Alegre, Universidade Federal do Rio Grande do Sul: v. 1, p. 01-10, 2006.

SALAMONI, G.; ACEVEDO, H. C.; ESTRELA, L. C. (orgs.). Os Pomeranos: valores culturais da família de origem pomerana no Rio Grande do Sul - Pelotas e São Lourenço do Sul. Pelotas: Universidade Federal de Pelotas, Editora Universitária, 1995.

SCHNEIDER, M. N. As (des)sonorizações e a neutralização da vibrante: atitudes e concepções linguísticas. In: Revista Contingentia, v. 3, n. 2, p. 77-88, 2008.

- Variação e discriminação linguística no ensino e aprendizagem de línguas em comunidades bilíngues. In: Calidoscópio. São Leopoldo: Universidade Federal do Vale do Rio dos Sinos, v. 7, n. 1 janeiro/abril, p. 79-85, 2009.

SILVA, F. B. Produção oral e escrita dos róticos em Arroio do Padre (RS): avaliando a relação português/pomerano com base na fonologia gestual. 2015. Dissertação (Mestrado): Programa de Pós-Graduação em Letras. Centro de Letras e Comunicação, Universidade Federal de Pelotas.

SILVA, S. S. A Colônia do rio Uvá: um contexto de imigração alemã e deslocamento linguístico. In: SILVA, S. S. (org.). Línguas em Contato: cenários de bilinguismo no Brasil. Campinas, SP: Pontes Editores, 2011, p. 117-140.

SOUZA, M. A.; PINTO, N. B.; ENS, R. T.. As contribuições da etnografia para a pesquisa educacional. II Seminário de Pesquisa e estudos qualitativos: a pesquisa qualitativa em debate.; Anais: Bauru, 2004. Disponível em: <http://www.sepq.org.br/IIsipeq/anais/pdf/gt2/07.pdf>. Acesso em: 30 de maio de 2014.

THUM, C. Educação, história e memória: silêncios e reinvenções pomeranas na Serra dos Tapes. Tese (Doutorado em Educação) - Programa de Pós-Graduação em Educação, Unisinos, São Leopoldo, 2009.

TRESSMANN, I. O pomerano: uma língua baixo-saxônica. In: Educação, Cultura, Sociedade. Revista da Farese. Santa Maria de Jetibá, Faculdade da Região Serrana: v. 1, p. 10-21, 2008. Disponível em: <http://www.farese.edu.br/pages/artigos/pdf/ismael/ O\%20POMERANO\%20-\%20UMA\%20L\%C3\%8DNGUA\%20B.-

SAX\%C3\%94NICA\%20(Revista\%20da\%20Farese).pdf. Acesso em: 15 de maio de 2013. 
WILLE, L.. Pomeranos no sul do Rio Grande do Sul: trajetória-mitos-cultura. Canoas: Ed. ULBRA, 2011.

Recebido em: 16/01/2017. Aceito em: 06/06/2017. 